\title{
The Polymerization of Azetidines and Azetidine Derivatives
}

\author{
E. J. Goethals, E. H. Schacht, Y. E. Bogaert, \\ S. I. ALI, and Y. TEZUKA \\ Institute of Organic Chemistry, Rijksuniversiteit-Gent, \\ Krijgslaan 271 (S4bis), B-9000 Ghent-Belgium.
}

(Received April 15, 1980)

\begin{abstract}
The cationic ring-opening polymerization of azetidine, $N$-alkylazetidines and a number of azetidines carrying a second functional group is reviewed. Some of these monomers lead to "living" polymers. The rate constants for the polymerization of different azetidines are discussed and compared with the rate constants for the polymerization of other four-membered heterocycles. The nucleophilic ring-opening polymerization of azetidinium salts is discussed. A new polymer with azetidinium endgroups is described. The synthesis, chemical properties, and applications of a number of polymers with pendant azetidinium substituents are described.
\end{abstract}

KEY WORDS Azetidine / $N$-Alkylazetidines / Azetidinium Salts / RingOpening Polymerization / Cationic Polymerization / Nucleophilic Polymerization / Copolymerization / Living Polymers / Block-Copolymers / Polyamines / Poly(ammonium salt)s /

Azetidines are four-membered ring amines. As all four-membered rings they have a high ring strain. ${ }^{1}$ Thermodynamically it is, therefore, expected that the ring-opening polymerization of these monomers leads to high-molecular-weight polymers in almost quantitative yields. Of all small ring compounds, the four-membered are generally the most difficult to synthesize. This is also true for azetidines and that is undoubtedly the reason why the polymerization of this class of compounds has received relatively little attention up to now. However, in the last two decades a number of new synthetic methods have been elaborated which allow to prepare a number of azetidine monomers in satisfactory yields starting from readily available materials. These methods have been reviewed recently. ${ }^{2}$

Alkylation of azetidines leads to azetidinium salts. These compounds also possess ring strain and can therefore be polymerized, although the accumulation of positive charges in the resulting macromolecules seems to prevent the obtention of high molecular weights. If the azetidinium functions are part of prepolymers, however, their "polymerization" can be used for cross-linking purposes or for the synthesis of block- and graft-copolymers.

\section{POLYMERIZATION OF AZETIDINES}

The polymerization of azetidines is a typical cationic ring-opening polymerization. The active species is the cyclic azetidinium ion and the propagation reaction may be regarded as a nucleophilic substitution at the $\alpha$-carbon atom of the azetidinium ion. Generally the polymerizations must be performed above room temperature.

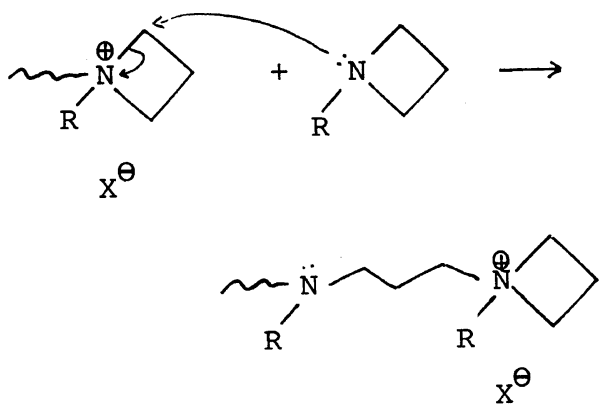

The initiation reaction for the polymerization of azetidines is the formation of an azetidinium salt. This can be achieved with proton acids or with alkylating agents, such as alkyl sulfates or sulfonates, trialkyloxonium salts, benzyl halides etc. In 


\section{E. J. Goethals, E. H. Schacht, Y. E. Bogaert, S. I. Ali, and Y. Tezuka}

many cases the monomeric azetidinium salt can be prepared separately and be used as the initiator. In this way the initiation reaction can be considered as quantitative at time zero of the polymerization. Lewis acids such as boron trifluoride, form stable complexes with azetidines, but these complexes themselves are probably not able to initiate the polymerization unless they are in the presence of a proton donor. For conidine (1-azabicyclo[4.2.0]octane) in methanol solution it was shown that the real initiation was protonation. ${ }^{3}$

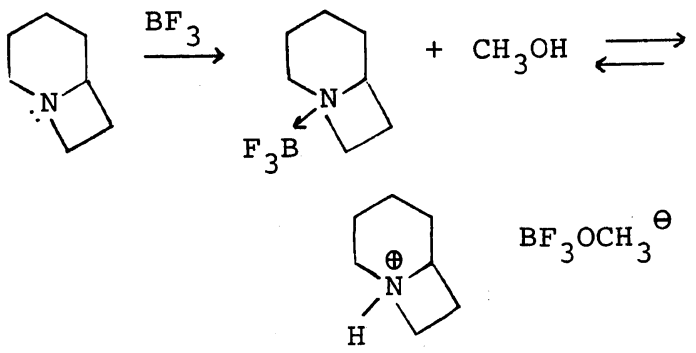

The driving force of the propagation reaction is the relief of the ring-strain. Since four-membered rings have a high ring strain, the polymerizations should, on the basis of the thermodynamics, be quantitative. However, as in many cationic ringopening polymerizations, the reaction can stop at limited conversions due to the occurence of termination reactions. ${ }^{4}$ These occur when the active species is opened by another nucleophile than monomer, whereby an active center has disappeared. During the polymerization, two of such nucleophilic reagents are present: the counterion and the amino functions of the formed polymer. Competition of the counterion can be avoided by choosing the initiating system so that the counterion is less nucleophilic than the monomer, which is not difficult due to the high nucleophilicity of amines. Counterions that present no problems include $\mathrm{BF}_{4}^{-}, \mathrm{ClO}_{4}^{-}, \mathrm{PF}_{6}{ }^{-}$, sulfates, and sulfonates. The halide anions behave differently. Chlorides and bromides seem not to terminate the polymerization of conidine $e^{5-7}$ whereas the polymerization of $1,3,3-$ trimethylazetidine was not possible with the chloride anion. ${ }^{8}$ Methyl iodide did initiate the polymerization of 1-(2-cyanoethyl)azetidine, ${ }^{9}$ conidine, ${ }^{10}$ and 1-(2-ethoxycarbonylethyl)azetidine. ${ }^{11}$ Termination reaction by nucleophilic attack of a polymeric amino function on the active species has been observed in the case of 1-methylazetidine. ${ }^{12}$

\section{Azetidine}

The polymerization of azetidine has been described by the present authors. ${ }^{13}$ This monomer polymerizes under the influence of various cationic initiators at temperatures above $60^{\circ} \mathrm{C}$. In methanol and with perchloric acid as initiator, the monomer is first converted into the dimer $N$-(3-aminopropyl)azetidine. The initiation reaction is obviously protonation of the monomer. The next step is a nucleophilic attack on the protonated monomer by another monomer molecule. The resulting reaction product is the protonated dimer which transfers its proton to the more basic monomer.
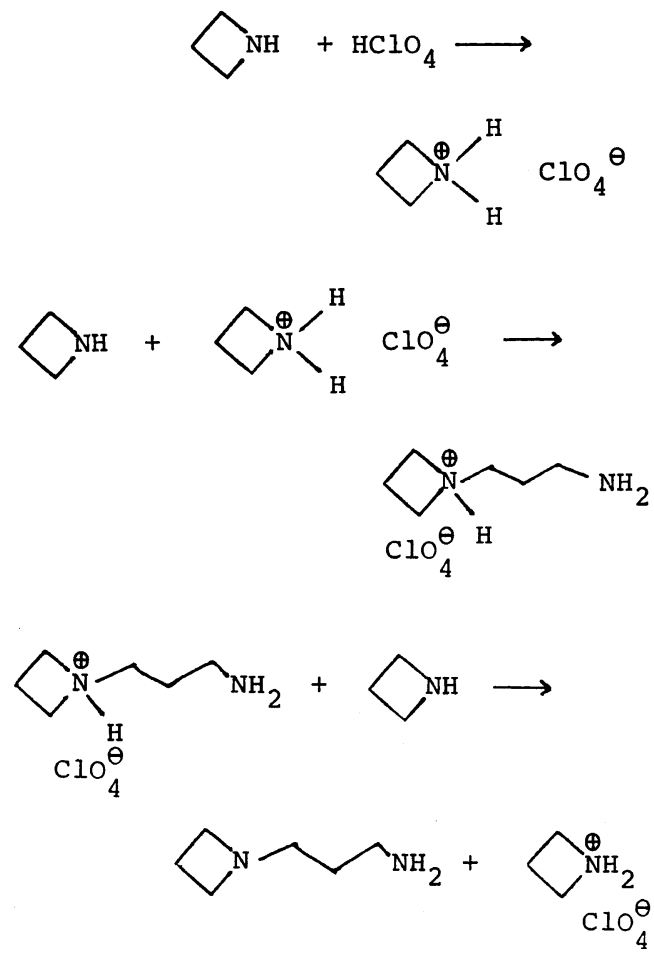

The dimer is formed rapidly at the beginning of the reaction, reaches a maximum abundance and disappears slowly after longer reaction times. When all monomer has reacted, $70 \%$ of the reaction mixture consists of the dimer, which can be regarded as a new "monomer" formed in situ. This compound now contains two nucleophilic sites-a primary and a tertiary amino function-which can both react with the active species for propagation. If only the primary amino group. would react, the polymer would have a linear structure 1 containing 
secondary amino groups. If only the tertiary amino group would react, the polymer would be a linear structure with pendant 3-aminopropyl substituents 2. If both functions react, a branched polymer would be formed containing primary, secondary and tertiary amino functions.

Reaction of secondary amino groups in the polymer with azetidinium salts can also lead to branched structures such as 3 .

$$
\begin{aligned}
& \begin{array}{cc}
\cdots-\mathrm{NH}-\mathrm{CH}_{2} \mathrm{CH}_{2} \mathrm{CH}_{2}-\cdots \cdot & \cdots-\mathrm{N}-\mathrm{CH}_{2} \mathrm{CH}_{2} \mathrm{CH}_{2}-\cdots \\
& \left(\mathrm{CH}_{2}\right)_{3} \\
& 1 \\
& \mathrm{NH}_{2} \\
&
\end{array} \\
& 1 \\
& \cdots-{ }_{\left(\mathrm{CH}_{2}\right)_{3}-\mathrm{CH}_{2} \mathrm{CH}_{2} \mathrm{CH}_{2}-\cdots}^{\cdots}
\end{aligned}
$$

The branched structure of the polymer was confirmed by ${ }^{1} \mathrm{H}$ NMR spectroscopy analysis. It was concluded that the polymer contained $20 \%$ of primary and tertiary amino groups and $60 \%$ of secondary amino groups, and consequently has a highly branched structure. This polymerization is, therefore, very similar to the polymerization of aziridine.

Saegusa ${ }^{14}$ has reported the synthesis of pure linear poly(trimethylenimine) (structure 1) by isomerization-polymerization of oxazine, followed by alkaline hydrolysis of the obtained polyamide. The polymer was a crystalline solid with $\mathrm{mp}$ between 74 and $84^{\circ} \mathrm{C}$ depending on the content of water of crystallization. The polymer obtained by cationic polymerization of azetidine on the contrary, is a viscous oil. This difference is obviously due to the occurrence of side chains in the latter polymer.

\section{$N$-Alkyl-Substituted Azetidines}

The first report on the polymerization of an azetidine was on conidine (1-aza-bicyclo[4.2.0]octane). The synthesis of this monomer and a few alkyl-substituted derivatives has been described by Lavagnino et al. in 1960 and in the same paper the authors describe that these compounds yield amorphous polymers when treated with a trace amount of methyl iodide or boron trifluoride etherate. ${ }^{10}$

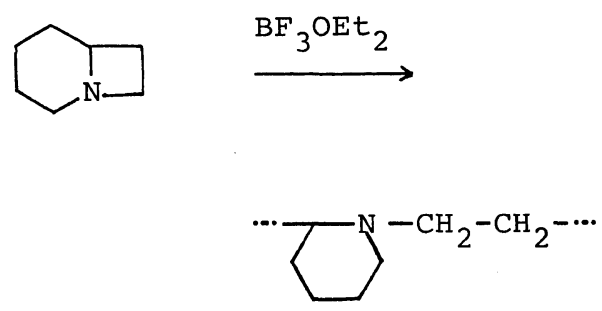

Toy and Price ${ }^{15}$ prepared the two pure enantiomers of conidine, which were also polymerized with boron trifluoride etherate. The polymer, with a strong optical rotation of opposite sign to that of the monomer from which it was formed, gave a sharply crystalline X-ray pattern and had a crystalline $\mathrm{mp}$ of $94^{\circ} \mathrm{C}$.

In 1971-1973 Razvodovski et al. published a number of papers on the mechanism of polymerization of a number of bicyclic amino monomers, among them conidine. ${ }^{5,7-9}$ The initiators were tertiary or quaternary ammonium salts derived from the monomer itself by reaction with a proton acid or an alkyl halide. From kinetic studies it was deduced that with quaternary ammonium salts as initiator, the concentration of active species remained constant during polymerization. The degrees of polymerization of the polymers were proportional to the extent of the reaction which proved that there are no transfer reactions. The polymerization was, therefore, considered as a typical "living" polymerization. With the boron trifluoride-conidine complex or tertiary ammonium salts as initiator, the polymerization showed an induction period which was attributed to a slow initiation process.

The polymerization of 1-methylazetidine and 1,3,3-trimethylazetidine with triethyloxonium tetrafluoroborate as initiator has been reported by the present authors. The first monomer polymerizes at room temperature and a termination reaction between the active species and an amino function of the polymer, leading to branched or macrocyclic ammonium salts, was observed. ${ }^{12}$ The polymerization of 1,3,3-trimethylazetidine ${ }^{8}$ is much slower. At room temperature, initiation to the azetidinium salt occurs immediately and quanti- 


\section{E. J. Goethals, E. H. Schacht, Y. E. Bogaert, S. I. Ali, and Y. TezuKa}

Table I. Rate constants and thermodynamic parameters for the polymerization of some azetidines

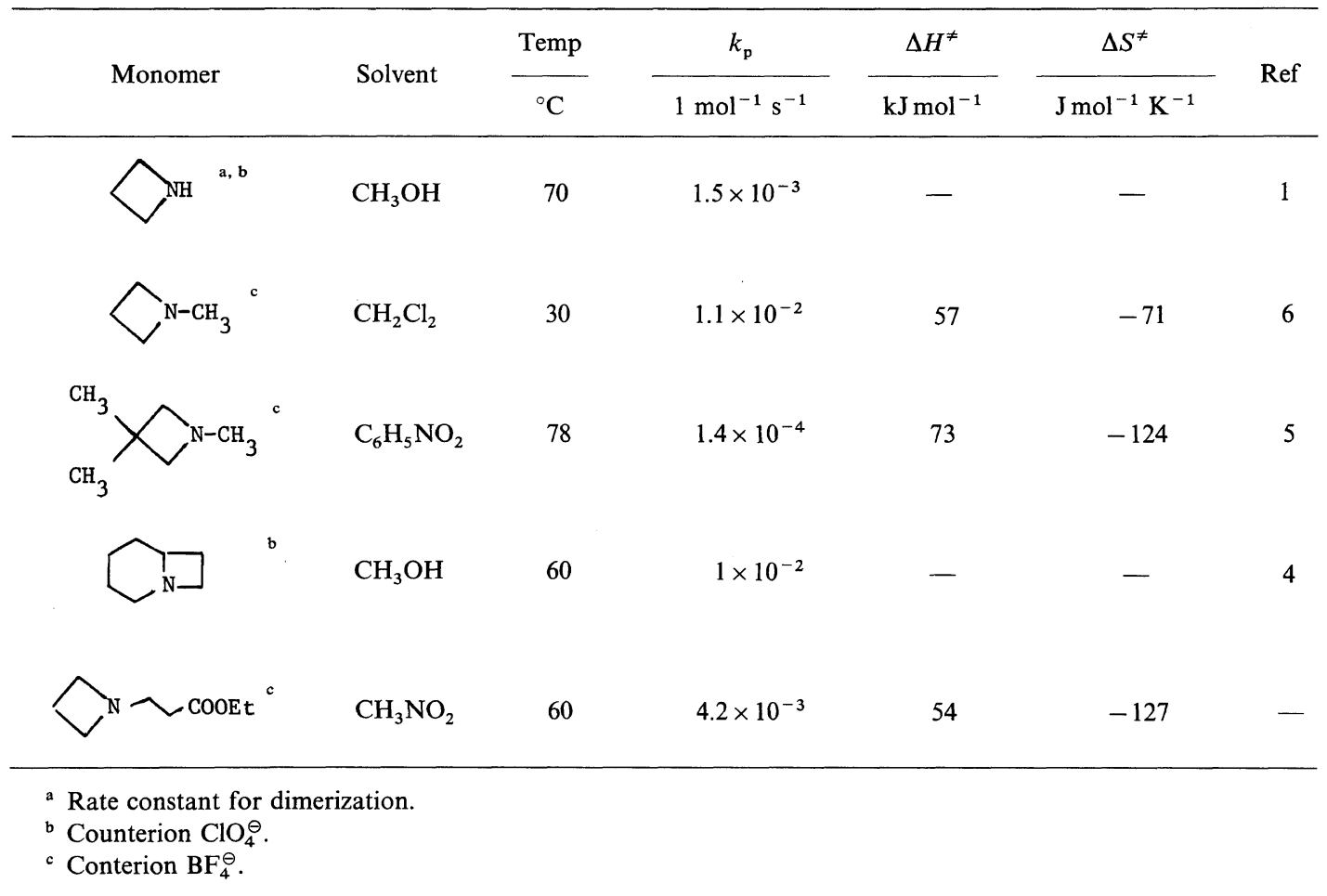

tatively but no polymerization takes place. At $60^{\circ} \mathrm{C}$ or higher, the polymerization goes to completion according to first-order kinetics. Second-monomer additions to completely polymerized reaction mixtures showed that the concentration of the active species remains constant during and even a long time after the polymerization. The active species could be observed directly by means of ${ }^{1} \mathrm{H}$ NMR spectroscopy and by this technique also, it was shown that their concentration does not change appreciably after several days at $78^{\circ} \mathrm{C} .{ }^{16}$ Consequently the polymerization of 1,3,3-trimethylazetidine is another example of a "living" cationic ring-opening polymerization.

Comparison of the polymerization behavior of 1methylazetidine and 1,3,3-trimethylazetidine shows the importance of the presence of gem-dimethyl substituents in the 3-position of the monomer. Although the absolute rate of polymerization decreases, it appears that the presence of these substituents retards the termination much more than the propagation which results in a higher living character. Analogous results have been found for the cationic polymerization of thietanes. ${ }^{17}$ The very important differences in "reactivities" of the monomethyl and the trimethyl monomers are reflected in the values of $k_{\mathrm{p}}$ and thermodynamical parameters, mentioned in Table I. These differences can in principle be due to a different reactivity of the monomers or to a different reactivity of the growing species or to both. Comparison of the homopolymerizations does not allow to decide which factor is predominant. Therefore the copolymerization of the two monomers has been studied. Figure 1 shows the copolymerization curve from which the following reactivity parameters (at $80^{\circ} \mathrm{C}$ in nitrobenzene) were deduced:

$$
r_{1}=\frac{k_{11}}{k_{12}}=3.3 \pm 0.2 \quad r_{2}=\frac{k_{22}}{k_{21}}=0.30 \pm 0.1
$$

These results prove that the reactivity of 1methylazetidine $\left(M_{1}\right)$ to both the active species is three times larger than that of 1,3,3-trimethylazetidine $\left(\mathrm{M}_{2}\right)$ to the same active species. The difference between the homopropagation constants $k_{11}$ and $k_{22}$ however, is a factor of approximately 
$10^{4}$ (as calculated from $\Delta H^{\ddagger}$ and $\Delta S^{\neq}$values). This clearly shows that the differences in reactivities in the homopolymerizations are in the first place governed by differences in reactivity of the active species, and only to a minor extent by the reactivities of the monomers. This result is logical since the driving force of these polymerizations is the ring-opening of the azetidinium end groups, the monomer acting only as a nucleophile which causes the ring-opening to occur.

Other $N$-alkylazetidines which have been polymerized are 1-cyanoethylazetidine, ${ }^{9}$ and 1-tbutylazetidine. ${ }^{18}$ In the last case the polymerization appears to have a high living character also, which

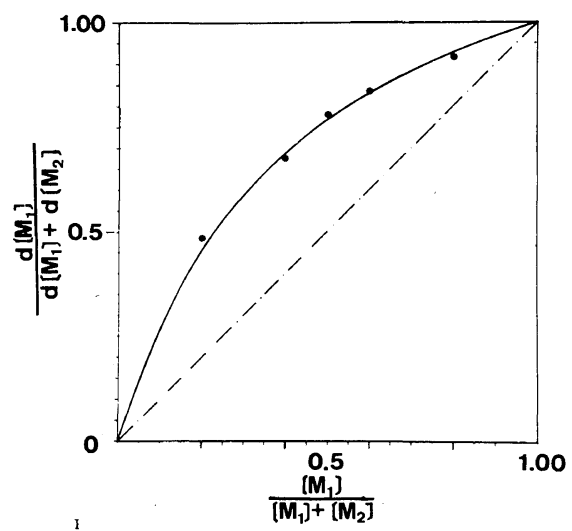

Figure 1. Copolymerization of $N$-methylazetidine $\left(\mathbf{M}_{1}\right)$ and 1,3,3-trimethylazetidine $\left(\mathbf{M}_{2}\right)$ in nitrobenzene at $80^{\circ} \mathrm{C}$. The curve corresponds to the reactivity parameters: $r_{1}=3.3$ and $r_{2}=0.3$. can be ascribed to the steric protection of the polymeric amino functions by the $t$-butyl groups.

Comparison of rate constants for the cationic polymerization of different four-membered heterocyclic monomers (Table II) leads to the conclusion that the ease of homopolymerization decreases in the order oxetanes $\gg$ thietanes $>$ azetidines. This order coincides with the order of reactivities of the corresponding classes of onium salts towards nucleophiles: oxonium $\gg$ sulfonium $>$ ammonium, and is the opposite of the order of nucleophilicity of the heteroatoms: amine $>$ sulfide $\gg$ ether. Again, this observation leads to the conclusion that the relative reactivities are in the first place dictated by the nature of the onium ion, i.e., the active chain end, and not by a property of the monomer (such as nucleophilicity or basicity of the hetero atom).

\section{Azetidines Containing a Second Functional Group}

In contrast with the simple azetidines described hitherto, a number of azetidines containing an additional functional group are easily prepared from simple starting materials.

Such compounds are 1-alkyl-3-azetidinols and 1ethoxycarbonylethylazetidine. Therefore the polymerization of these monomers were investigated in the hope that with them also, polymers with predictable molecular weight and living end groups would be obtained. The results were disappointing: although both kinds of monomers were polymerized in quantitative yields, the molecular weights were always lower than predicted for living systems.

Table II. Comparison of propagation constants for the cationic polymerization of different four-membered heterocyclic monomers ${ }^{a}$

\begin{tabular}{|c|c|c|c|c|}
\hline \multirow{2}{*}{ Monomer } & Temperature & \multirow{2}{*}{ Counterion } & $k_{\mathrm{p}}$ & \multirow{2}{*}{ Ref } \\
\hline & ${ }^{\circ} \mathrm{C}$ & & $1 \mathrm{~mol}^{-1} \mathrm{~s}^{-1}$ & \\
\hline & -30 & $\mathrm{PF}_{6}^{\ominus}$ & 9 & 19 \\
\hline & 0 & $\mathrm{BF}_{4}^{\ominus}$ & 0.16 & 20 \\
\hline & +30 & $\mathrm{BF}_{4}^{\ominus}$ & 0.010 & 12 \\
\hline
\end{tabular}

a Polymerizations performed in $\mathrm{CH}_{2} \mathrm{Cl}_{2}$. 
The azetidinols ${ }^{21}$ gave the corresponding hydroxy aminopolymers with molecular weights up to 2200 .<smiles>[R]N1CC(O)C1</smiles>

The nature of the transfer reaction which must take place during this polymerization is not yet understood.

1-(2-Ethoxycarbonylethyl)azetidine polymerizes to the corresponding poly(aminoester) $)^{11}$ at temperatures above $80^{\circ} \mathrm{C}$. Although initiation with tri-<smiles>CCCCN(C)CCC(=O)OCC</smiles>

ethyloxonium salts is rapid and quantitative, firstorder plots do not give the straight lines expected for living polymerizations. Also, the molecular weights, estimated by GPC, are markedly lower than predicted for a living polymer. However, addition of a new amount of monomer to a completely polymerized reaction mixture results in immediate polymerization at a rate which is about half that of the original polymerization.

These observations lead to the conclusion that there must be a transfer reaction which is most probably a Hoffman type of elimination whereby $\mathrm{HBF}_{4}$ is formed which is capable to re-initiate the polymerization:

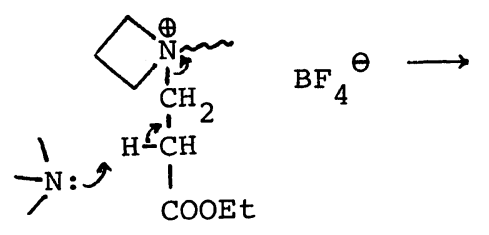

$$
\begin{aligned}
& \widehat{\mathrm{N}}^{\mathrm{N}}+\mathrm{CH}_{2}=\mathrm{CHCOOE} \mathrm{t} \\
& +-_{-}^{\oplus}{ }_{\mathrm{NH}}^{\mathrm{BF}}{ }_{4}^{\ominus}
\end{aligned}
$$

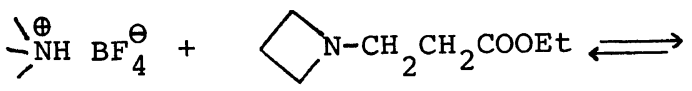

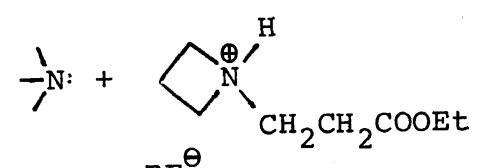

$$
\begin{aligned}
& \mathrm{BF}_{4}^{\ominus}
\end{aligned}
$$

This possibility was confirmed by studying the behavior of a model azetidinium salt under polymerization conditions:

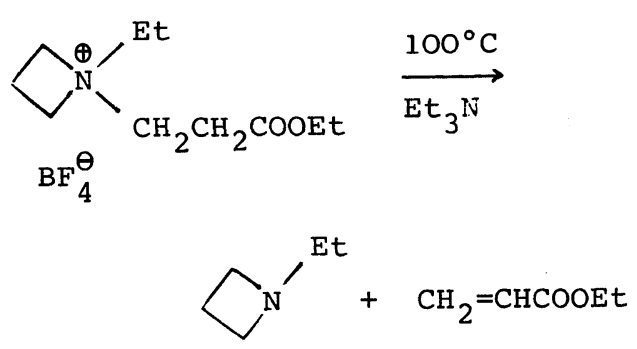

A solution of the salt remains unchanged after several hours of heating at $100^{\circ} \mathrm{C}$ but in the presence of a tertiary amine, a rapid formation of ethyl acrylate is observed. During the polymerization, the growing species are obviously in the presence of tertiary amines.

\section{POLYMERIZATION OF AZETIDINIUM SALTS}

The propagation reaction in the polymerization of azetidines is an attack of the nucleophilic monomer on the electrophilic azetidinium ion at the chain end of the growing polymer molecule. Inversely, one can envisage that azetidinium salts can be polymerized under the influence of a nucleophile such as a tertiary amine:<smiles>[R19]CCCC1CC[N+]1([R])[R]</smiles> 


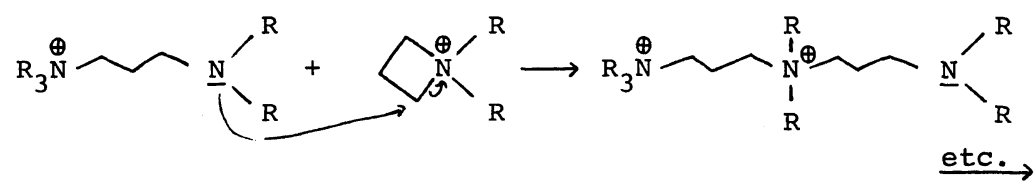

In this way a polymerization with a nucleophile as the growing species occurs (which, in analogy with "cationic," "anionic," "radical" polymerizations, could be called "nucleophilic" polymerization). The resulting polymer is of the ionene type. The difficulty in this kind of polymerization is, that as the number of cationic charges on the same molecule increases, it becomes more difficult to add another azetidinium monomer. For example, attempts to polymerize 1-ethyl-1,3,3-trimethylazetidinium tetrafluoroborate with triethylamine failed because the reaction stopped after the first addition:

$$
\begin{aligned}
& \mathrm{Et}_{3} \mathrm{~N}:+{ }_{\mathrm{CH}_{3}}^{\mathrm{CH}_{3}} \overbrace{\mathrm{C}_{2} \mathrm{H}_{5}}^{\stackrel{\oplus}{\mathrm{N}}}{ }_{\mathrm{BF}_{4}}^{\mathrm{CH}_{3}} \longrightarrow
\end{aligned}
$$

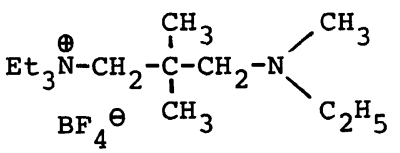

Recently, Yamashita et al. have reported the polymerization of a number of azetidinium salts derived from benzylazetidine and cyanoethylazetidine. ${ }^{28}$ The polymerization were performed in bulk at the melting temperature of the monomers, or at approximately $70^{\circ} \mathrm{C}$ in dimethylformamide solution. With iodide as counterion the polymerization started without addition of an initiator. With tosylate as counterion, a tertiary amine was necessary to initiate the polymerization.

The same authors have reported the polymerization of 1-benzyl-1-(2-carboxyethyl)azetidinium zwitterion, which proceeds via an attack of the carboxylate anion on the azetidinium ion leading to a poly(imino ester) ${ }^{22}$ :

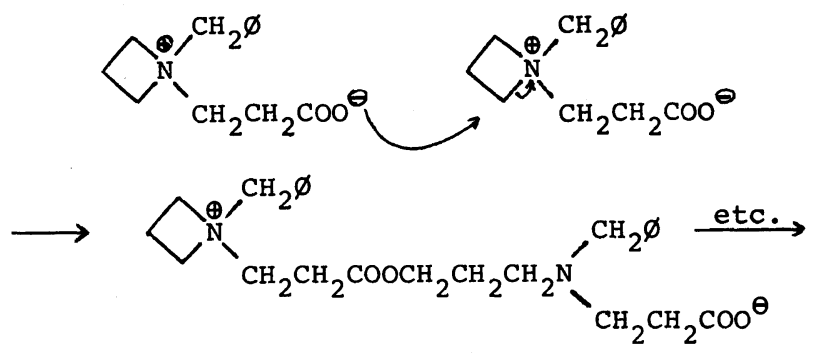

This mechanism is analogous to that proposed earlier by Saegusa et al. for the spontaneous alternating copolymerization of 1,3,3-trimethylazetidine and acrylic acid. ${ }^{23}$

\section{SYNTHESIS AND REACTIONS OF POLYMERS WITH AZETIDINIUM ENDGROUPS}

The polymerization of tetrahydrofuran (THF) initiated with an ester of triflic acid leads to a living polymer with one oxonium ion as chain end. ${ }^{24,25}$ When the polymerization is initiated with triflic anhydride, the polymer has two active oxonium chain ends. ${ }^{26}$ Since it was shown that $N$ alkylazetidines react rapidly and quantitatively with oxonium salts to form the corresponding azetidinium salts, the addition of an alkylazetidine with such a living poly(THF) should lead to the corresponding azetidinium-terminated polymers. This possibility was checked and confirmed in the case of 1,3,3-trimethylazetidine: 

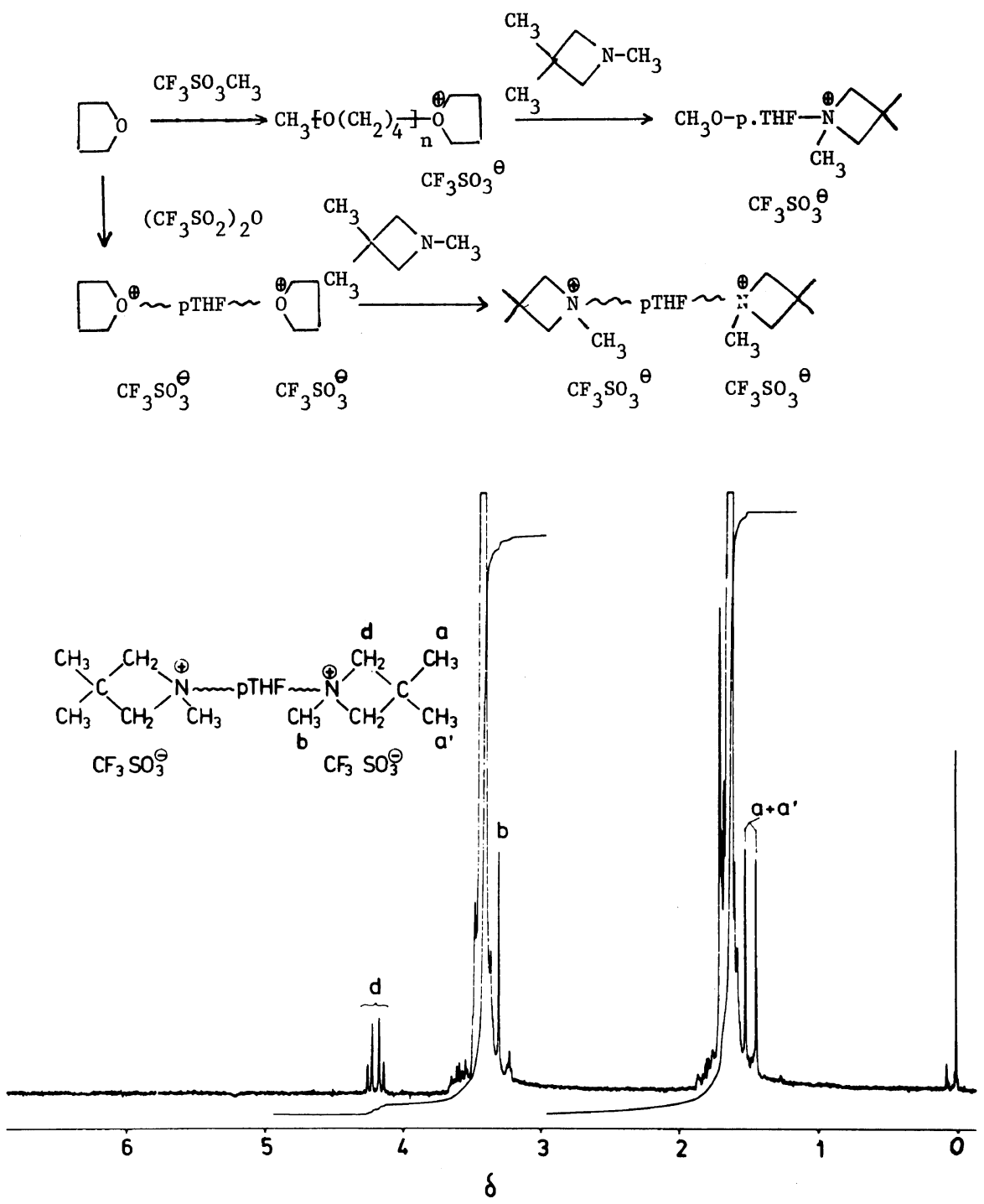

Figure 2. $360 \mathrm{MHz}{ }^{1} \mathrm{H}$ NMR spectrum of azetidinium-terminated poly(tetrahydrofuran).

Figure 2 shows the NMR spectrum of such a polymer. Next to the two main peaks due to the poly(THF) protons, the typical $\mathrm{AB}$ pattern of the asymmetrically substituted azetidinium ion at $\delta \simeq 4.15$ is clearly visible. Also the gem-dimethyl groups $(\delta=1.4)$ and the ammonium methyl $(\delta=3.2)$ are present.

The obtained polymers are colorless powders which are stable for many months at room temperature. They are mono- or bi-functional telechelic polymers with electrophilic endgroups. When treated with 1,3,3-trimethylazetidine at $100^{\circ} \mathrm{C}, \mathrm{A}-\mathrm{B}-\mathrm{A}$ type of block-copolymers are produced. Reaction with a polyfunctional nucleophile such as diethylenetriamine leads to high-molecularweight polymers and eventually to cross-linking. Combination with amino-terminated polybutadiene polymers, leads to polyblock copolymers. 
POLYMERS CONTAINING AZETIDINE

OR AZETIDINIUM FUNCTIONS AS PENDANT GROUPS

Several polymers containing azetidinium functions substituted on their polymer backbone, have been synthesized. Such polymers are produced on a commercial scale by reacting a polyamine-amide (derived from diethylenetriamine and adipic acid) with epichlorohydrin. ${ }^{27}$

This reaction is similar to the preparation of $\mathrm{N}$ alkyl-3-azetidinols.

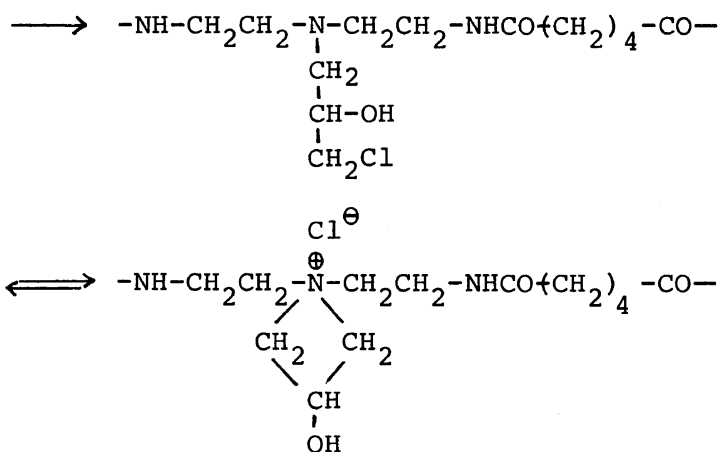

The presence of azetidinium salt functions in the polymer was confirmed by ${ }^{1} \mathrm{H}$ NMR spectroscopy study of the polymer and of low-molecular-weight model substances. ${ }^{28}$ This water-soluble polymer is sold under various trade names and finds uses as wet-strength additive in the paper fabrication, as anti-shrink additive for wool, and as hairstyling material.

Reaction of vinylbenzyl chloride with 1,3,3trimethylazetidine leads to the corresponding quaternary azetidinium salt which can be polymerized by radical initiators:<smiles>C=Cc1cccc(CCCCCc2cccc(C=C)c2)c1</smiles><smiles>CCC(C)c1cccc(C[N+]2(C)CC(C)(C)C2)c1</smiles>

This polymer is soluble in methanol and in waterTHF. It cross-links by heating or by addition of a polymaine such as diethylenetriamine.
Polymerization of the methacryl esters of $N$-alkyl3-azetidinols leads to polymers with pendant azetidine groups. ${ }^{29}$ When treated with hydrochloric 
acid, the polymers become water-soluble. Contrarily to the commercial products, these polymethacrylate polymers can be conserved in dry form without showing any tendency for cross-linking (at room-temperature).

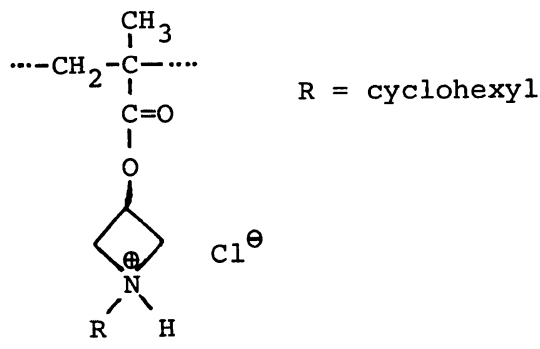

By heating them at $130^{\circ} \mathrm{C}$ during 2 minutes they become insoluble. These polymers show analogous properties as anti-shrinkage additive for wool as the commercial polyazetidinium product. This is a confirmation that these properties are related to the azetidinium function of the polymers. The reason for the non-shrinkage of wool fibers treated with this kind of polymers is that the polymer forms a thin smooth layer on the surface of the fiber. ${ }^{30}$ Probably the polymer is cross-linked as a consequence of the heat treatment of the fiber according to a mechanism similar to the azetidinium salt polymerization:

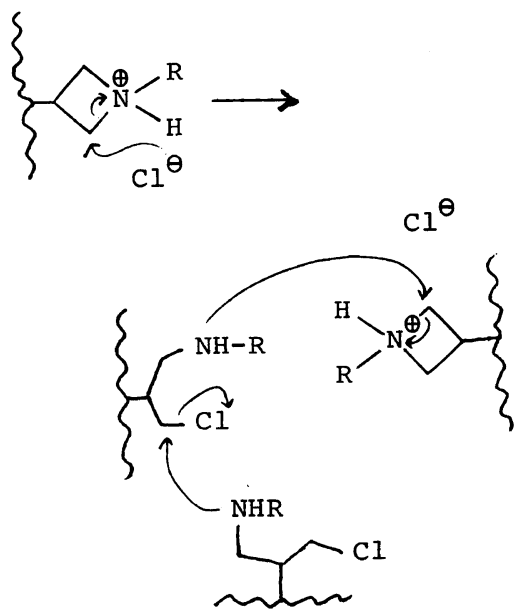

Copolymers of the azetidinium methacrylate with methyl methacrylate and with styrene have been described. ${ }^{29}$ The hydrochloride salts are watersoluble when the polymers contain approximately $50 \%$ of ammonium salt units (or more).

\section{REFERENCES}

1. A. S. Pell and G. Pilcher, Trans. Faraday Soc., 61, 71 (1965).

2. E. J. Goethals and E. H. Schacht in "Polymeric Amines and Ammonium Salts," E. J. Goethanls, Ed., Pergamon Press, Oxford, 1980, p 67.

3. I. S. Morozova et al., Dokl. Akad. Nauk SSSR, 209, 133 (1973).

4. E. J. Goethals, J. Polym. Sci., Polym. Symp., No. 56, 271 (1976).

5. E. F. Razvodovskii, A. Nekrasov, A. A. Berlin, A. T. Ponomarenko, and N. S. Enikolopyan, Dokl. Akad. Nauk SSSR, 198, 894 (1971).

6. E. F. Razvodovskii, A. A. Berlin, A. V. Nekrasov, Z. M. Pushchayeva, N. G. Puchkova, and N. S. Enikolopyan, Vysokomol. Soedin Ser., A, 15, 2219 (1973).

7. E. F. Razvodovskii, A. A. Berlin, A. V. Nekrasov, A. T. Ponomarenko, L. M. Pushchayeva, N. G. Puchkova, and N. S. Enikolopyan, Vysokomol. Soedin Ser. A, 15, 2233 (1973).

8. E. H. Schacht and E. J. Goethals, Makromol. Chem., 167, 155 (1973).

9. S. Hashimoto and T. Yamashita, Polym. J., 9, 19 (1977).

10. E. R. Lavagnino, R. R. Chauvette, W. N. Cannon, and E. C. Kornfeld, J. Am. Chem. Soc., 82, 2609 (1960).

11. J. Luckasczyk, E. H. Schacht, and E. J. Goethals, Makromol. Chem. Rapid Commun., 1, 79 (1980).

12. E. H. Schacht, P. Bossaer, and E. J. Goethals, Polym. J., 9, 329 (1977).

13. E. H. Schacht and E. J. Goethals, Makromol. Chem., 175, 3447 (1974).

14. T. Saegusa, Y. Nagura, and S. Kobayashi, Macromolecules, 6, 495 (1973). '

15. M. S. Toy and C. C. Price, J. Am. Chem. Soc., 82, 2613 (1960).

16. E. J. Goethals and E. H. Schacht, J. Polym. Sci. Polym. Lett. Ed., 11, 497 (1973).

17. E. J. Goethals, W. Drijvers, D. Van Ooteghem, and A. M. Buyle, J. Macromol. Sci., Chem., A7, 1375 (1973).

18. E. H. Schacht and E. J. Goethals, unpublished results.

19. P. E. Black and D. J. Worsfold, Can. J. Chem., 54, 3325 (1976).

20. A. M. Buyle and E. J. Goethals, unpublished results.

21. K. Banthia, E. H. Schacht, and E. J. Goethals, Makromol. Chem., 179, 841 (1978).

22. S. Hashimoto and T. Yamashita in "Polymeric Amines and Ammonium Salts," E. J. Goethals, Ed., Pergamon Press, Oxford, 1980, p 79.

23. T. Saegusa, Y. Kimura, S. Sawada, and S. Kobayashi, Macromolecules, 7,956 (1974).

24. K. Matyjaszewski, P. Kubisa, and S. Penczek, J. 
Polym. Sci., Poym. Chem. Ed., 12, 1333 and 1905 (1974).

25. S. Koayashi, H. Danda, and T. Saegusa, Macromolecules, 7, 415 (1974).

26. S. Smith, W. J. Schultz, and R. A. Newmark in "Ring-Opening Polymerization," ACS Symposium Series No. 59, T. Saegusa and E. J. Goethals, Ed., 1977, p 13.

27. R. H. Earle Jr., R. H. Saunders, and L. R. Kangas, $J$. Appl. Polym. Sci., Appl. Polym. Symp., 18, 707
(1971).

28. E. J. Goethals and A. K. Banthia, unpublished results.

29. E. H. Schacht, Y. Bogaert, and E. J. Goethals, Paper presented at the IUPAC Symposium on Macromolecules, Mainz, September 1979.

30. H. Baumann, M. Hienzch, B. Kamien, E. Goethals, and Y. Bogaert in "Polymeric Amines and Ammonium Salts," E. J. Goethals, Ed., Pergamon Press, Oxford, 1980, p 377. 